\title{
Characteristics of Creep Damage for 60Sn-40Pb Solder Material
}

\author{
Y. Wei and C. L. Chow \\ Department of Mechanical Engineering \\ University of Michigan-Dearborn \\ Dearborn, Michigan 48128
}

and

\section{ABSTRACT}

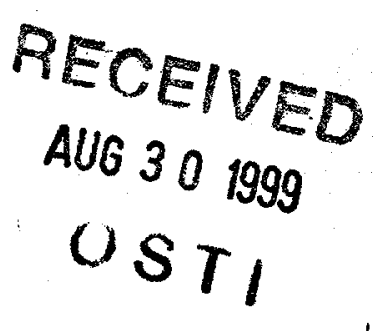

This paper presents a viscoplasticity model taking into account the effects of change in grain or phase size and damage on the characterization of creep damage in $60 \mathrm{Sn}-40 \mathrm{~Pb}$ solder. Based on the theory of damage mechanics, a two-scalar damage model is developed for isotropic materials by introducing the free energy equivalence principle. The damage evolution equations are derived in terms of the damage energy release rates. In addition, a failure criterion is developed based on the postulation that a material element is said to have ruptured when the total damage accumulated in the element reaches a critical value.

The damage coupled viscoplasticity model is discretized and coded in a general-purpose finite element program known as ABAQUS through its user-defined material subroutine UMAT. To illustrate the application of the model, several example cases are introduced to analyze, both numerically and experimentally, the tensile creep behaviors of the material at three stress levels. The model is then applied to predict the deformation of a notched specimen under monotonic tension at room temperature $\left(22^{\circ} \mathrm{C}\right)$. The results demonstrate that the proposed model can successfully predict the viscoplastic behavior of the solder material.

\section{Introduction}

The $\mathrm{Pb}-\mathrm{Sn}$ eutectic alloy acts as both electrical and mechanical connection within and among the different surface mount packaging levels in an electronic device. A critical consideration in characterizing aging of solder joint material for electronic packaging is its viscoplastic behavior. This is because the $\mathrm{Pb}-\mathrm{Sn}$ eutectic solder is highly rate sensitive and temperature dependent. A realistic constitutive model for the solder material is required in order to predict accurately the reliability of solder joints under service conditions.

A number of viscoplastic models have been used for the solder material in the past (Busso, et al., 1992, 1994, Frear, et al., 1997, Fu, et al., 1998, Pao, et al., 1994). In 
general, the viscoplastic flow rule follows the power function, the exponential function, or the hyperbolic-sine function. Most models do not include the effects of the grain size ( $\mathrm{Pb}$-rich phase size) but assume that the initial grain or phase size is a material constant that does not change under load. However, experimental evidence indicates that during service loading, coarsening occurs and the related microstructural evolution should be considered. Frear, et al. (1997) developed a model that incorporates the grain or phase size as an internal state variable that evolves during numerical simulation. The model has been applied to simulate thermomechanical fatigue behavior in solder joints.

Most current methods of analysis for the prediction of solder joint reliability assume a solder joint material to be free of micro-defects. It is, however, well accepted that most materials contain numerous micro-voids/cracks and the evolution of these defects causes material degradation or damage during service (Lemaitre and Chaboche, 1990). To characterize microstructural changes in materials, a few models have been developed for different materials based on the concept of damage mechanics (Chow, et al., 1987, 1991, 1999, Ju, et al., 1996, Hansen, et al., 1994, Hayakawa, et al. 1997, Krajcinovic, et al., 1981) and the disturbed state concept proposed by Desai (Basaran, et al., 1998). In this paper, a viscoplasticity model is developed for the solder material by incorporating the effects of grain or phase size and material damage on its creep behavior. The model is applied to examine the viscoplastic behavior of $60 \mathrm{Sn}-40 \mathrm{~Pb}$ solder under tension.

\section{Constitutive Model}

\subsection{Free energy equivalence principle}

According to damage mechanics, several damage variables, known as internal state variables, are introduced to quantify material degradation at the macro-scale level. These damage variables are used to define effective stress and effective back stress. The relationship between the true stress $\sigma$ and the effective stress $\bar{\sigma}$ is established with the damage effect tensor $\mathbf{M}$ as:

$$
\bar{\sigma}=\mathbf{M}: \sigma
$$

and the relationship between the effective back stress $\overline{\mathbf{X}}$ and true back stress $\mathbf{X}$ is defined by

$$
\overline{\mathbf{X}}=\mathbf{M}: \mathbf{X}
$$

Past experimental observations have revealed that the values of Young's modulus and Poisson's ratio decrease with increase in load. Accordingly an anisotropic fatigue damage model has been developed to characterize the solder material (Fang, et al 1998). Past investigations have however shown that fatigue damage is a localized phenomenon where material may be assumed to undergo isotropic rather than anisotropic damage (Chow and Wei, 1991). Taking into account the experimental observation coupled with the assumption that the isotropic behavior of the solder material prevails under load, the form of the damage effect tensor is developed, without loss of generality and accuracy, in terms of two scalar damage variables $D$ and $\mu$ as (Chow, et al., 1991, 1999) 


\section{DISCLAIMER}

This report was prepared as an account of work sponsored by an agency of the United States Government. Neither the United States Government nor any agency thereof, nor any of their employees, make any warranty, express or implied, or assumes any legal liability or responsibility for the accuracy, completeness, or usefulness of any information, apparatus, product, or process disclosed, or represents that its use would not infringe privately owned rights. Reference herein to any specific commercial product, process, or service by trade name, trademark, manufacturer, or otherwise does not necessarily constitute or imply its endorsement, recommendation, or favoring by the United States Government or any agency thereof. The views and opinions of authors expressed herein do not necessarily state or reflect those of the United States Government or any agency thereof. 


\section{DISCLAIMER}

Portions of this document may be illegible in electronic image products. Images are produced from the best available original document. 


$$
\mathbf{M}=\frac{1}{1-D}\left[\begin{array}{cccccc}
1 & \mu & \mu & 0 & 0 & 0 \\
\mu & 1 & \mu & 0 & 0 & 0 \\
\mu & \mu & 1 & 0 & 0 & 0 \\
0 & 0 & 0 & 1-\mu & 0 & 0 \\
0 & 0 & 0 & 0 & 1-\mu & 0 \\
0 & 0 & 0 & 0 & 0 & 1-\mu
\end{array}\right]
$$

This tensor reduces to the conventional scalar form when the variable $\mu$ equals zero. Physically the variable $\mu$ may be interpreted as a measure of damage associated with change in Poisson's ratio.

For a solder without damage consideration, the free energy is given as

$$
\Psi=W^{e}+\Psi^{k}=\frac{1}{2} \sigma^{T}: \mathbf{C}_{0}^{-1}: \sigma+\frac{3}{4} C_{k 0}^{-1} \mathbf{X}^{T}: \mathbf{X}
$$

where $W^{e}$ is the elastic energy, $\Psi^{k}$ is the kinematic hardening part of free energy, $\mathbf{C}_{0}$ is the fourth order elastic tensor and $C_{k 0}$ is the material parameter for kinematic hardening.

In order to consider the effects of damage on the state of a material, the free energy equivalence principle is postulated as: the free energy for a damaged material may be expressed in a form similar to that for a material without damage except that all stresses (true stress and back stress) are replaced by their corresponding effective stresses. Therefore, the free energy for damaged materials is expressed with equation (4) as

$$
\begin{aligned}
\Psi & =\frac{1}{2} \bar{\sigma}^{T}: \mathbf{C}_{0}^{-1}: \bar{\sigma}+\frac{3}{4} C_{k 0}^{-1} \overline{\mathbf{X}}^{T}: \overline{\mathbf{X}} \\
& =\frac{1}{2} \sigma^{T}: \mathbf{M}^{T}: \mathbf{C}_{0}^{-1}: \mathbf{M}: \sigma+\frac{3}{4} C_{k 0}^{-1} \mathbf{X}^{T}: \mathbf{M}^{T}: \mathbf{M}: \mathbf{X} \\
& =\frac{1}{2} \sigma^{T}: \mathbf{C}^{-1}: \sigma+\frac{3}{4} C_{k 0}^{-1} \mathbf{X}^{T}: \mathbf{M}^{T}: \mathbf{M}: \mathbf{X}
\end{aligned}
$$

where $\mathbf{C}^{-1}$ is the effective elastic tensor for a damaged material and can be derived with the form of the damage effect tensor in equation (3) as

$$
\mathbf{C}^{-1}=\mathbf{M}^{T}: \mathbf{C}_{0}^{-1}: \mathbf{M}=\frac{1}{E}\left[\begin{array}{rrrrrr}
1 & -v & -v & 0 & 0 & 0 \\
-v & 1 & -v & 0 & 0 & 0 \\
-v & -v & 1 & 0 & 0 & 0 \\
0 & 0 & 0 & 2(1+v) & 0 & 0 \\
0 & 0 & 0 & 0 & 2(1+v) & 0 \\
0 & 0 & 0 & 0 & 0 & 2(1+v)
\end{array}\right]
$$

$E$ and $v$ in Equation (6) are the Young's modulus and the Poisson's ratio for a damaged material, and can be expressed in terms of the damage variables $D$ and $\mu$ as 


$$
\begin{gathered}
E=\frac{E_{0}(1-D)^{2}}{1-4 v_{0} \mu+2\left(1-v_{0}\right) \mu^{2}} \\
v=\frac{v_{0}-2\left(1-v_{0}\right) \mu-\left(1-3 v_{0}\right) \mu^{2}}{1-4 v_{0} \mu+2\left(1-v_{0}\right) \mu^{2}}
\end{gathered}
$$

$E_{0}$ and $v_{0}$ are the Young's modulus and the Poisson's ratio for undamaged or as-received material. It is obvious from equation (7) that the Poisson's ratio does not change if the value of $\mu$ equals zero.

The free energy in Equation (5) can be reduced with the form of damage effect tensor in equation (6) as

$$
\Psi=\frac{1}{2} \sigma^{T}: \mathbf{C}^{-1}: \sigma+\frac{3}{4} C_{k}^{-1} \mathbf{X}^{T}: \mathbf{X}
$$

where $C_{k}$, as a kinematic hardening variable for a damaged material, is derived with Equation (3) as

$$
C_{k}^{-1}=\frac{(1-\mu)^{2}}{(1-D)^{2}} C_{k 0}^{-1}
$$

Obviously, the damage effects on both elastic part and inelastic part of the free energy have been taken into account within equation (8).

\subsection{Damage energy release rate}

The damage energy release rates corresponding to the damage variables $D$ and $\mu$ are derived with the free energy in Equation (8) based on the theory of irreversible thermodynamics as

$$
\begin{aligned}
& Y_{D}(\sigma, \mathbf{X}, D, \mu)=-\frac{\partial \Psi}{\partial D}=-\frac{1}{1-D} \sigma^{T}: \mathbf{C}^{-1}: \sigma-\frac{3}{2} \frac{C_{k}^{-1}}{1-D} \mathbf{X}^{T}: \mathbf{X} \\
& Y_{\mu}(\sigma, \mathbf{X}, D, \mu)=-\frac{\partial \Psi}{\partial \mu}=-\frac{1}{1-D} \sigma^{T}: \mathbf{Z}: \sigma+\frac{3}{2} \frac{C_{k}^{-1}}{1-\mu} \mathbf{X}^{T}: \mathbf{X}
\end{aligned}
$$

where the form of tensor $\mathbf{Z}$ is derived as

$$
\begin{aligned}
& \mathbf{Z}=\frac{1}{E_{0}(1-D)}\left[\begin{array}{cccccc}
z_{1} & z_{2} & z_{2} & 0 & 0 & 0 \\
z_{2} & z_{1} & z_{2} & 0 & 0 & 0 \\
z_{2} & z_{2} & z_{1} & 0 & 0 & 0 \\
0 & 0 & 0 & 2\left(z_{1}-z_{2}\right) & 0 & 0 \\
0 & 0 & 0 & 0 & 2\left(z_{1}-z_{2}\right) & 0 \\
0 & 0 & 0 & 0 & 0 & 2\left(z_{1}-z_{2}\right)
\end{array}\right] \\
& z_{1}=2 \mu\left(1-v_{0}\right)-2 v_{0}
\end{aligned}
$$




\subsection{Damage coupled constitutive equations}

With the free energy in Equation (8), the elastic equation is derived as

$$
\begin{aligned}
& \varepsilon^{e}=\frac{\partial \Psi}{\partial \sigma}=\mathrm{C}^{-1}: \sigma \\
& \sigma=\mathbf{C}: \varepsilon^{e}
\end{aligned}
$$

and the kinematic hardening equation is derived as

$$
\begin{aligned}
& \alpha_{k}=\frac{\partial \Psi}{\partial \mathbf{X}}=\frac{3}{2} C_{k}^{-1} \mathbf{X} \\
& \mathbf{X}=\frac{2}{3} C_{k} \alpha_{k}
\end{aligned}
$$

where $\varepsilon^{e}$ is the elastic tensor and $\alpha_{k}$ is the back strain tensor.

The inelastic constitutive equation is given by coupling damage with the viscoplastic flow rule developed by Frear, et al. (1997) as

$$
\dot{\varepsilon}^{i n}=\frac{3(1-\mu)}{2(1-D)} f \exp \left(\frac{-Q}{R \theta}\right)\left(\frac{\lambda_{0}}{\lambda}\right)^{p} \sinh ^{m}\left(\frac{1-\mu}{1-D} \frac{J_{2}}{\alpha(c+\hat{c})}\right) \frac{\mathbf{S}-\mathbf{X}}{J_{2}}
$$

where $\dot{\varepsilon}^{i n}$ is the true inelastic strain tensor, $J_{2}$ is a second invariant of the stress difference and defined as

$$
J_{2}=\left\{\frac{3}{2}(\mathbf{S}-\mathbf{X})^{T}:(\mathbf{S}-\mathbf{X})\right\}^{\frac{1}{2}}
$$

$\mathrm{S}$ is the deviatoric stress, $f, p, m$ and $Q$ are material parameters, $R$ is the gas constant, $\theta$ is the absolute temperature, $\lambda$ is the current grain diameter, $\lambda_{0}$ is the initial grain diameter, $\alpha$ is a scalar function of the absolute temperature, and $c$ and $\hat{c}$ are state variables. Therefore, the equivalent inelastic strain rate can be defined as

$$
\dot{p}^{i n}=\left\{\frac{2}{3} \dot{\varepsilon}^{i n, T}: \dot{\varepsilon}^{i n}\right\}^{\frac{1}{2}}=\frac{1-\mu}{1-D} f \exp \left(\frac{-Q}{R \theta}\right)\left(\frac{\lambda_{0}}{\lambda}\right)^{p} \sinh ^{m}\left(\frac{1-\mu}{1-D} \frac{J_{2}}{\alpha(c+\hat{c})}\right)
$$

Accordingly, the inelastic constitutive equation (15) can be expressed in a simple form as

$$
\dot{\varepsilon}^{i n}=\dot{p}^{i n} \frac{3}{2} \frac{\mathbf{S}-\mathbf{X}}{J_{2}}
$$

Therefore, the total strain is calculated with the following equation

$$
\varepsilon=\varepsilon^{e}+\varepsilon^{i n}
$$

According to the model developed by Frear, et al. (1997), the back strain tensor can be expressed as

$$
\dot{\alpha}_{k}=\dot{\varepsilon}^{\text {in }}-C_{k 0}\left(A_{5} \dot{p}^{\text {in }}+A_{6}\right) \alpha_{k} \sqrt{\frac{2}{3} \alpha_{k}^{T}: \alpha_{k}}
$$

where $A_{5}$ and $A_{6}$ are material constants. The scalar state variable $c$ is given by

$$
\dot{c}=A_{1} \dot{p}^{\text {in }}-\left(A_{2} \dot{p}^{\text {in }}+A_{3}\right)\left(c-c_{0}\right)^{2}
$$


where $c_{0}, A_{1}, A_{2}$ and $A_{3}$ are material parameters. The state variable $\hat{c}$ is related to the grain diameter $\lambda$ by

$$
\hat{c}=A_{7}\left(\frac{\lambda_{0}}{\lambda}\right)^{A_{8}}
$$

where $A_{7}$ and $A_{8}$ are positive material parameters, and $\lambda_{0}$ is the initial grain diameter. The evolution of the grain diameter is given by

$$
\dot{\lambda}=A_{11} \frac{\mathrm{v}_{\mathrm{x}}+\mathrm{v}_{0}}{\lambda}
$$

where $A_{11}$ is a material parameter, $\mathrm{v}_{\mathrm{x}}$ is the excess vacancy concentration, and $\mathrm{v}_{0}$ is the initial vacancy concentration. The evolution of the vacancy concentration is

$$
\dot{\mathrm{v}}_{\mathrm{x}}=A_{9} \dot{p}^{\text {in }}-A_{10} \mathrm{v}_{\mathrm{x}}
$$

where $A_{9}$ and $A_{10}$ are material parameters.

\subsection{Inelastic damage evolution equations}

The equivalent inelastic damage energy release rate, $Y_{\text {ind }}$, is defined as

$$
Y_{\text {ind }}=\left[\frac{1}{2}\left(Y_{D}^{2}+\gamma Y_{\mu}^{2}\right)\right]^{1 / 2}
$$

where $\gamma$ is the damage evolution coefficient, $Y_{D}$ and $Y_{\mu}$ are the thermodynamic conjugate forces of the inelastic damage variables $D$ and $\mu$ defined in Equations (10) and (11). Then, the overall inelastic damage rate is proposed with the equivalent inelastic damage energy release rate as

$$
\dot{w}=\dot{p}^{\text {in }}\left(\frac{Y_{\text {ind }}}{Y_{h}}\right)^{b_{1}}
$$

where $b_{1}$ is a material constant and $Y_{h}$ is the inelastic damage hardening variable which may be expressed in terms of the overall inelastic damage $w$. Therefore, the temperature and strain rate effects on the inelastic damage evolution are included in Equation (26) through the equivalent inelastic strain $p^{\text {in }}$ expressed by Equation (17). The form of inelastic damage hardening function $Y_{h}(w)$ is given for the solder material as

$$
Y_{h}(w)=Y_{0} e^{b_{2} w}
$$

where $Y_{0}$ and $b_{2}$ are material constants. Accordingly, the inelastic damage evolution equations are given as

$$
\dot{D}=-\dot{w} \frac{Y_{D}}{2 Y_{\text {ind }}} \quad \dot{\mu}=-\dot{w} \frac{\gamma Y_{\mu}}{2 Y_{\text {ind }}}
$$

A failure criterion is proposed based on overall inelastic damage accumulation. The criterion postulates that a material element is failed or ruptured when the overall inelastic damage $w$ reaches its critical value $w_{c}$.

The damage coupled viscoplasticity model is coded in a general-purpose finite element program known as ABAQUS through its user-defined material subroutine UMAT. A complete description of the finite element coding and the testing methods for the 
determination of the material parameters required by the model will be reported separately.

\section{Applications}

The proposed micro-macro damage model contains a total of 27 material parameters including 5 damage parameters. Material parameters were obtained from a nonlinear least squares fit to a variety of uniaxial compression and creep compression experiments. The nonlinear least squares fit to the experimental data was obtained using the Levenburg-Marquardt Algorithm (More, 1978) which was coupled to a driver subroutine that exercised the constitutive model and generated uniaxial compression and creep compression response predictions for any prescribed set of material parameters. The stress-strain curves at different strain rates for tensile tests, the strain-time curves at different initial stress for creep tests, and the changes of Young's modulus and Poisson's ratio under a load were measured for the determination of all necessary material parameters. The maximum strain applied for the stress-strain curve and the creep behavior are 6\%. The measurements for Young's modulus and Poisson's ratio were carried out at certain strain intervals until final rupture. The material parameters calculated for the as-received $60 \mathrm{Sn}-40 \mathrm{~Pb}$ plate chosen for the investigation are summarized in Table 1. The validation of the proposed viscoplastic damage model was carried out with two example cases. One case involves tensile creep of $60 \mathrm{Sn}-40 \mathrm{~Pb}$ at three stress levels and the second one considers monotonic tension of a notched specimen made of $60 \mathrm{Sn}-40 \mathrm{~Pb}$ under two loading rates at a constant temperature $\left(22^{\circ} \mathrm{C}\right)$.

The creep tests were conducted at three stress levels, namely $2000 \mathrm{psi}, 3000 \mathrm{psi}$ and 4050 psi, at $22^{\circ} \mathrm{C}$ under load control. In the finite element analyses, a linear, full-integration brick element, known as C3D8 in ABAQUS, was used. Two viscoplasticity models were used to predict the creep behavior; one is the proposed damage model, and another one is the model developed by Frear, et al. (1997) without damage consideration. The results of the finite element simulation with and without damage consideration and the test results are shown in Figure 1. At the end of the initial time interval, the predicted results with both models are the same due to negligible damage accumulation. With increase in time, the deviation in creep strains between the two models becomes large due to damage accumulation. It can be observed from the figure that the creep behavior of $60 \mathrm{Sn}-40 \mathrm{~Pb}$ can be more accurately predicted with the damage model than the Frear model.

It is of interest to note that the viscoplastic damage model appears to over-estimate the creep life at higher loads (i.e. 3000 psi and 4050 psi) but under-estimate the life at the lower load of 2000psi. The inconsistency in the prediction may be attributed to the quality and quantity in the measurement of material test data. It is a monumental and ongoing task to devise a well-controlled experimental series for the eutectic material which is known to be dependent not only on temperature and strain rate but also on their effect on grain coarsening.

The damage model has also been applied to predict damage distributions in the notched specimen shown in Figure 2 under monotonic tension. The notched specimens were 


\section{REFERENCES}

1. Basaran, C., Desai, C.S. and Kundu, T., 1998, "Thermomechanical finite element analysis of problems in electronic packaging using the disturbed state concept: Part 1theory and formulation", ASME Journal of Electronic Packaging, Vol.120, pp.41-47.

2. Busso, E.P., Kitano, M. and Kumazawa, 1992, "A visco-plastic constitutive model for 60/40 Tin-Lead solder used in IC package joints", ASME Journal of Engineering materials and Technology, Vol.114, pp.331-337.

3. Busso, E.P., Kitano, M. and Kumazawa, 1994, "Modeling complex inelastic deformation processes in IC packages' solder joints", ASME Journal of Electronic Packaging, Vol.116, pp. 6-15.

4. Chow, C.L. and Wang, J., 1987, "An anisotropic theory of continuum damage mechanics for ductile fracture", Engineering Fracture Mechanics, Vol.27, pp.547558 .

5. Chow, C.L. and Wei, Y., 1991, "A model of continuum damage mechanics for fatigue fracture", Internal Journal of Fracture, Vol.50, pp.301-316.

6. Chow, C.L. and Wei, Y., 1999, "On constitutive modeling of material damage for fatigue failure prediction, International Journal of Damage Mechanics.

7. Fang, H. Eliot, Chow, C.L. and Yang, F., 1998 "A method of damage mechanics analysis for solder material", Fracture and Strength of Solids - Part 2 : Behavior of Materials and Structures, pp. 367-374

8. Frear, D.R., Burchett, S.N., Neilsen, M.K. and Stephens, J.J., 1997, "Microstructurally based finite element simulation of solder joint behavior", Soldering \& Surface Mount Technology, No.25, pp.39-42.

9. Fu, C., McDowell, D.L. and Ume, I.C., 1998, "A finite element procedure of a cyclic thermoviscoplasticity model for solder and copper interconnects" ASME Journal of Electronic Packaging, Vol.120, pp.24-34.

10. Hansen, N. R. and Schreyer, H.L., 1994, "A thermodynamically consistent framework for theories of elastoplasticity coupled with damage", International Journal of Solids and Structure, Vol.31, pp.359-389.

11. Hayakawa, K. and Murakami, S., 1997, "Thermodynamical modeling of elasticplastic damage and experimental validation of damage potential", International Journal of Damage Mechanics, Vol.6, pp.333-363.

12. Ju, S.H., Sandor, B.I. and Plesha, M.E., 1996, "Life prediction of solder joints by damage and fracture mechanics", ASME Journal of Electronic Packaging, Vol.118, pp.193-200.

13. Krajcinovic, D. and Fonseka, G.U., 1981, "The continuous damage mechanics of brittle materials, Parts I and II", ASME Journal of Applied Mechanics, Vol.48, pp.809-824.

14. Lemaitre, J. and Chaboche, J.L., 1990, Mechanics of Solid Materials, Cambridge University Press.

15. More, J. J., 1978, "The Levenburg-Marquardt Algorithm: Implementation and Theory", Lecture Notes in Mathematics 630, edited by G. A. Watson, SpringerVerlag 
16. Pao, Y.-H., Badgley, S., Govila, R. and E. Jih, 1994, "Thermomechanical and fatigue behavior of high-temperature lead and lead-free solder joints", ASTM STP 1153, Fatigue of Electronic Materials, pp.60-81.

Table 1 Material Parameters - 60/40 Solder

\begin{tabular}{|l|c|l|c|}
\hline \multicolumn{1}{|c|}{ Property } & Value & \multicolumn{1}{c|}{ Property } & Value \\
\hline Young's modulus (mpa) & $33.26 \times 10^{3}$ & Grain Exponent $\mathrm{p}$ & 3 \\
\hline Poisson's ratio & 0.40 & Flow stress $\mathrm{c}_{0}(\mathrm{mpa})$ & 3.45 \\
\hline $\mathrm{A}_{1}(\mathrm{mpa})$ & 0 & Grain size $\lambda_{0}(\mathrm{~mm})$ & $8.99 \times 10^{-4}$ \\
\hline $\mathrm{A}_{2}(1 / \mathrm{mpa})$ & 0 & Vacancy concentration $\mathrm{v}_{0}$ & $1.00 \times 10^{-9}$ \\
\hline $\mathrm{A}_{3}(1 / \mathrm{mpa}-\mathrm{sec})$ & 0 & Flow rate $\mathrm{f}(1 / \mathrm{sec})$ & $1.566 \times 10^{6}$ \\
\hline $\mathrm{A}_{4}$ or $\mathrm{C}_{\mathrm{k} 0}(\mathrm{psi})$ & $35.19 \times 10^{3}$ & Temperature factor $\alpha$ & 1 \\
\hline $\mathrm{A}_{5}(1 / \mathrm{mpa})$ & 49.41 & Activation energy $\mathrm{Q}(\mathrm{cal} / \mathrm{mol})$ & $1.376 \times 10^{4}$ \\
\hline $\mathrm{A}_{6}(1 / \mathrm{mpa}-\mathrm{sec})$ & $2.61 \times 10^{-2}$ & Gas constant $\mathrm{R}(\mathrm{cal} / \mathrm{mol}-\mathrm{K})$ & 1.987 \\
\hline $\mathrm{A}_{7}(\mathrm{mpa})$ & 3.45 & $\mathrm{~b}_{1}$ & 0.4 \\
\hline $\mathrm{A}_{8}$ & 0.5 & $\mathrm{~b}_{2}$ & 5.0 \\
\hline $\mathrm{A}_{9}$ & $1.00 \times 10^{-3}$ & $\mathrm{Y}_{0}(\mathrm{mpa})$ & $9.52 \times 10^{-2}$ \\
\hline $\mathrm{A}_{10}(1 / \mathrm{sec})$ & 16.67 & $\gamma$ & -0.665 \\
\hline $\mathrm{A}_{11}\left(\mathrm{~mm}^{2} / \mathrm{sec}\right)$ & $3.75 \times 10^{-2}$ & critical value $\mathrm{w}_{\mathrm{c}}$ & 0.21 \\
\hline Sinh Exponent $\mathrm{m}$ & 3.04 & & \\
\hline
\end{tabular}

Table 2 Maximum loads of notched specimen $(\mathrm{N})$

\begin{tabular}{|c|c|c|c|}
\hline \multirow{2}{*}{$\begin{array}{c}\text { loading rate } \\
(\mathrm{mm} / \mathrm{s})\end{array}$} & \multicolumn{2}{|c|}{ numerical result } & \multirow{2}{*}{ measured result } \\
\cline { 2 - 3 } & C3D8R & C3D8 & \\
\hline $2.7 \times 10^{-3}$ & 162.9 & 168.7 & 170.1 \\
\hline $9.66 \times 10^{-4}$ & 114.8 & 116.6 & 120.5 \\
\hline
\end{tabular}




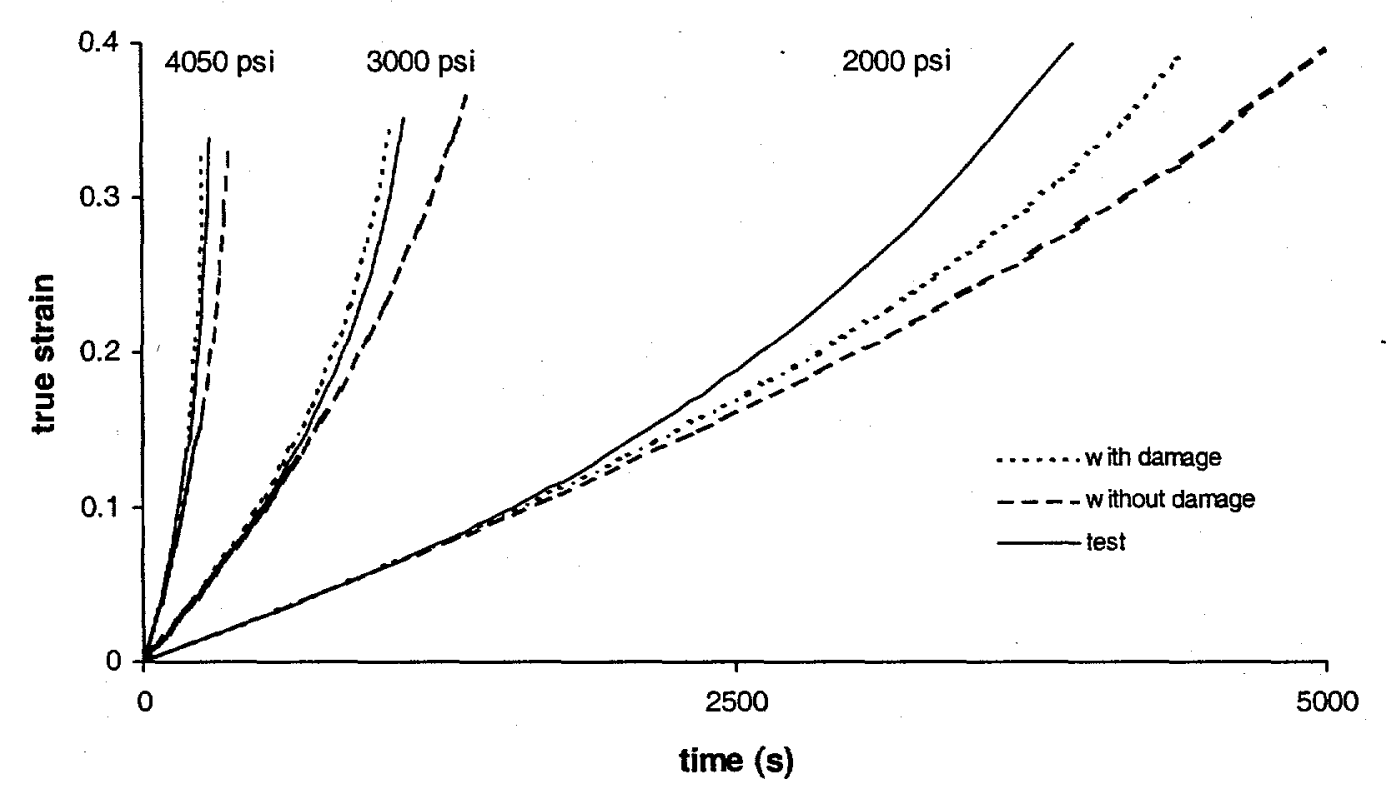

Fig. 1 Creep behavior of $60 \mathrm{Sn}-40 \mathrm{~Pb}$ for three stress levels

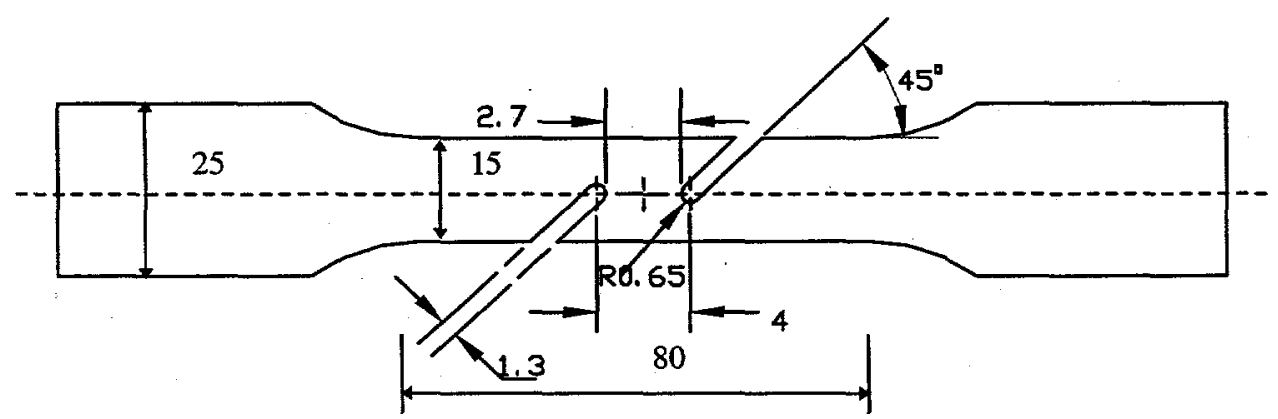

Fig.2 Specimen Configurations (all unit:mm) 


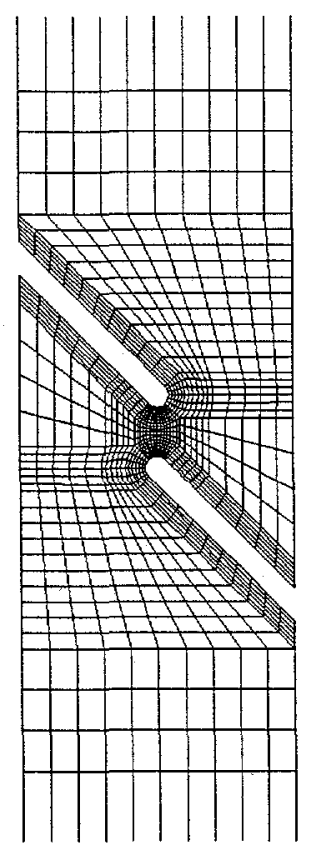

Fig. 3 Undeformed elements at notch area

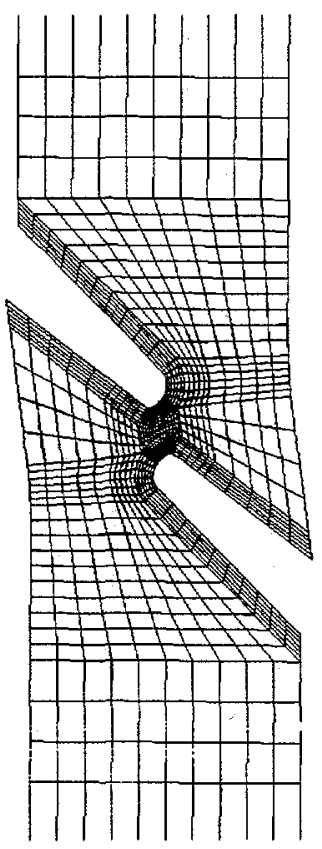

Fig. 4 Deformed elements at notch area 


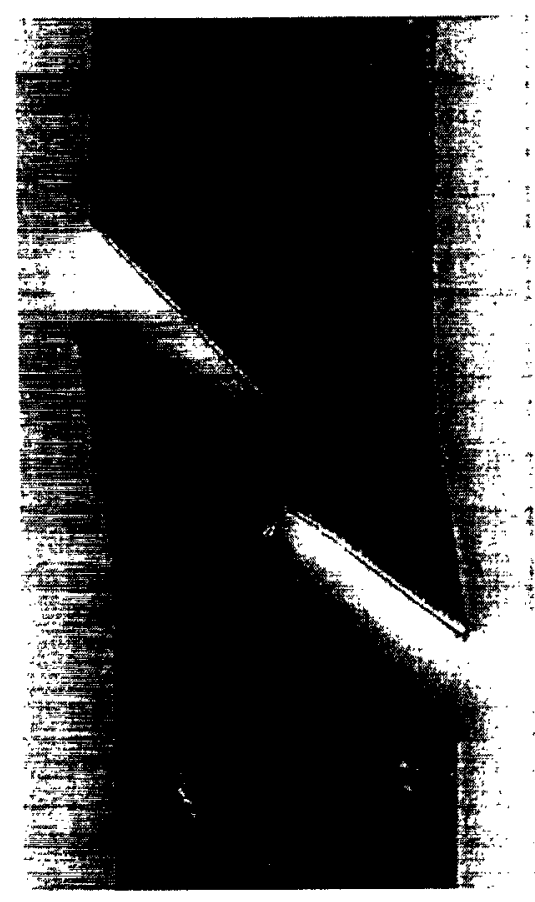

Fig.5 Deformed specimen under monotonic tension

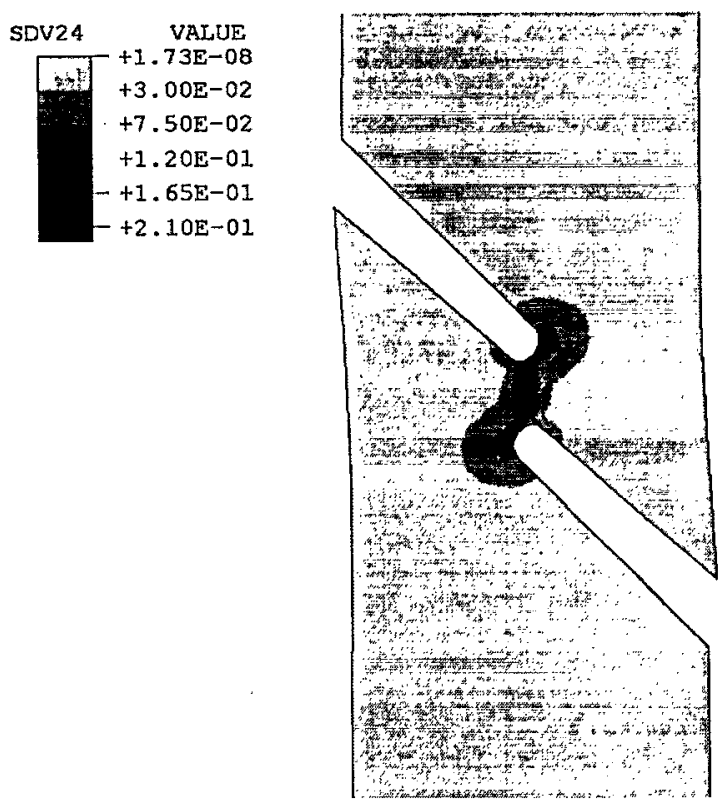

Fig.6 Contours of overall damage at displacement $0.98 \mathrm{~mm}$ at loading rate $2.7 \times 10^{-3} \mathrm{~mm} / \mathrm{s}$ 

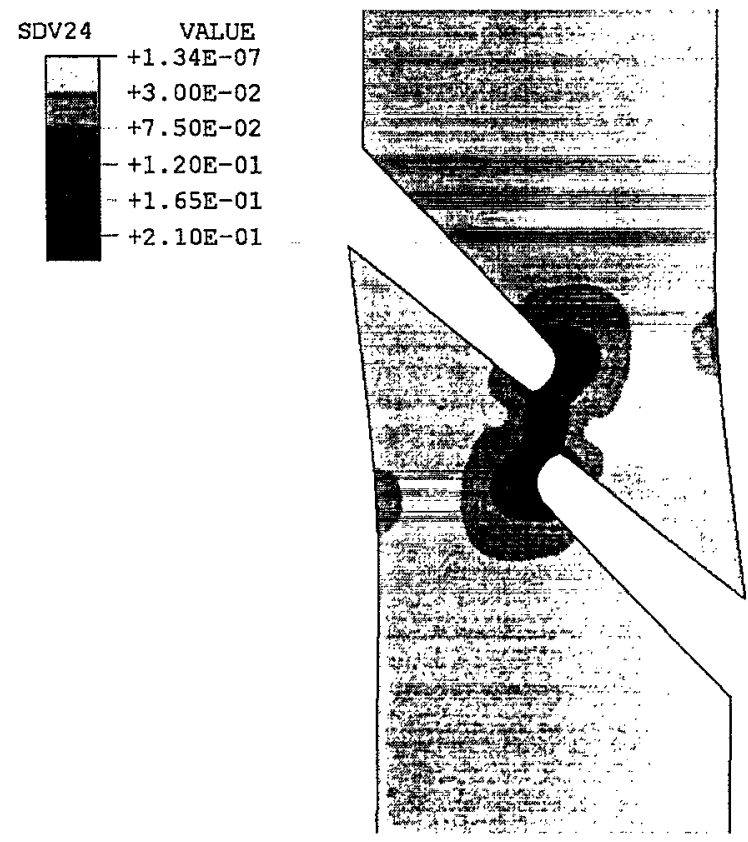

Fig.7 Contours of overall damage at displacement $2.08 \mathrm{~mm}$ at loading rate $2.7 \times 10^{-3} \mathrm{~mm} / \mathrm{s}$ 